\title{
Las editoriales españolas en las redes sociales: presencia, actividad y compromiso
}

\author{
Spanish publishers on social networks: presence, activity and \\ engagement
}

\author{
Magadán-Díaz, M. y Rivas-García, J. ${ }^{1}$ \\ Recibido: 21-09-2019 - Aceptado: 10-02-2020 \\ DOI: https://doi.org/10.26441/RC19.1-2020-A9
}

\begin{abstract}
RESUMEN: Esta investigación tiene como objetivo general abordar el modo en que las veinticinco primeras editoriales españolas en publicación de literatura gestionan sus redes sociales. Para ello, por medio del modelo PRGS, se analiza el peso de las principales redes sociales (Facebook, Twitter e Instagram) en la estrategia de marketing digital de las empresas editoriales españolas desde una triple dimensión: a) la atracción de usuarios, b) la generación de contenidos, y c) el compromiso de los usuarios con la marca. Del estudio realizado sobre las editoriales españolas se concluye que Facebook es la que más fans genera, frente a Twitter e Instagram. Sin embargo, Twitter es la red más aprovechada para generar contenidos. Finalmente, en lo tocante al compromiso, los resultados apuntan a Instagram como la red donde se obtienen mejores resultados.
\end{abstract}

Palabras clave: red social; Facebook; Twitter; Instagram; editorial; modelo PRGS; España.

\begin{abstract}
The general goal of this research is to address the way in which the twenty-five first Spanish publishers in literature publication manage their social networks. For this, through the PRGS model, the weight of the main social networks (Facebook, Twitter and Instagram) in the digital marketing strategy of these Spanish publishing companies is analysed from a triple dimension: a) the attraction of users, b) content generation, and c) users' engagement to the brand. The study conducted on these twenty-five Spanish publishers concludes that Facebook is the one that generates the most fans, compared to Twitter and Instagram. Nonetheless, Twitter is the network most used to generate content. Finally, in terms of engagement, the results point out Instagram as the network where better results are obtained.
\end{abstract}

Keywords: Social network; Facebook; Twitter; Instagram; publishing company; PRGS model; Spain.

\footnotetext{
${ }^{1}$ Marta Magadán-Díaz es Doctora en Administración de Empresas por la Universidad de Oviedo, profesora de la Universidad Internacional de la Rioja y CEO en la industria editorial; dirige Las Tertulias del Campoamor de la Fundación Municipal de Cultura del Ayuntamiento de Oviedo. Fue presidenta del Gremio de Editores de Asturias y formó parte de la junta directiva de la Federación de Gremio de Editores de España. marta.magadan@unir.net, https://orcid.org/0000-0003-3178-3215

Jesús Rivas-García es Doctor en Economía por la Universidad de Oviedo y profesor de la Universidad Internacional de la Rioja. Director del Máster Universitario en Dirección de Operaciones y Calidad en la misma universidad. Fue profesor en la Universidad de Oviedo y profesor visitante en las universidades de Guadalajara y Colima. Desarrolló labores de asesoramiento y consultoría estratégica para empresas e instituciones públicas. jesus.rivas@ unir.net, https://orcid.org/0000-0003-0576-5961
} 


\section{Introducción}

En la última década, el impacto transversal del sector tecnológico sobre el editorial ha provocado su mayor transformación desde la aparición de la imprenta con Gutenberg (Carreiro, 2010; Magadán y Rivas, 2018). La rápida difusión y mejora de las herramientas informáticas y de Internet ha dado lugar a que los bienes y servicios culturales se produzcan y distribuyan de una manera diferente a la empleada para sus soportes físicos, exigiendo al sector editorial una adaptación de sus procesos operacionales a los nuevos continentes (Terzi, 2011; Martin y Tian, 2016), promoviendo, al tiempo, un cambio notable en los hábitos de consumo (Hibbert, 1999; Lichtenberg, 2011).

Los avances y desarrollos de las tecnologías de la información y comunicación (en adelante, TICs) están causando cambios notables en las formas en que las editoriales y los lectores se comunican entre sí, lo que han permitido: a) la evolución y uso de plataformas orientadas de manera específica a la interacción personal (Del Fresno, 2014; Zhu y Chen, 2015) y b) que las TICs sean reconocidas como nuevas y potentes herramientas de marketing para dar a conocer un producto, un servicio o un negocio (Dwivedi, Kapoor y Chen, 2015; Hawkins y Vel, 2013).

Las redes sociales han ido mutando de espacios virtuales de interacción colectiva a medios de comunicación, difusión e intercambio de información de un valor estratégico crucial para los responsables de marketing tanto de las organizaciones empresariales, en general, como de las empresas editoriales, en particular (Alalwan et al., 2017; Hawkins y Vel, 2013; Rathore, Ilavarasan y Dwivedi, 2016).

De manera específica, la contribución de las redes sociales, tanto a la estrategia de marketing de las empresas como a su comunicación corporativa, se puede evidenciar en aspectos como: a) la participación interactiva de los consumidores, potenciando la co-creación (Coulter y Roggeveen, 2012) y b) la gestión de las relaciones con estos (Filo, Lock y Karg, 2015; Saxena y Khanna, 2013). Todo ello está modificando el comportamiento del consumidor (Algharabat et al., 2017; Kaplan y Haenlein, 2010), con importantes consecuencias para las empresas, productos y marcas (Hinz et al., 2011) que no pueden mantenerse ajenas a los cambios del microentorno.

Aunque las revistas, periódicos y otros medios de comunicación tradicionales siguen siendo importantes para la difusión de las novedades editoriales, su dominio está disminuyendo en favor de los medios digitales. Las redes sociales representan un canal de comunicación más innovador y rentable que brinda a los clientes una alta interactividad e individualización (Leeflang et al., 2014). La nueva gama de medios empleados en el sector editorial abarca, entre otros: videos hechos para la Web (booktrailers), catálogos por Internet, correo electrónico (mailing), blogs, contenido para teléfonos móviles (mobile content marketing) o redes sociales online. En definitiva, las editoriales están haciendo menos difusión masiva (broadcasting) y más difusión dirigida (narrowcasting), invirtiendo recursos en diseñar sus estrategias de marketing utilizando aplicaciones de medios sociales que les permiten transmitir la información requerida y recibir los comentarios proporcionados por los usuarios de aquellas (potenciales consumidores) de un modo automático y preciso (Rathore, Ilavarasan y Dwivedi, 2016).

Esta investigación tiene como objetivo analizar, a través del uso del modelo PRGS, el papel e influencia de Facebook, Twitter e Instagram en la estrategia de marketing digital de las empresas editoriales españolas desde una triple perspectiva: a) atracción de usuarios, b) generación de contenidos, y c) compromiso de los usuarios con la marca.

El trabajo está estructurado de la siguiente manera: la sección dos hace una breve exposición del marco teórico de las redes sociales; la sección tres proporciona una visión de la metodología utilizada; la sección cuatro presenta el análisis de datos; finalmente, la última sección condensa las conclusiones del estudio realizado. 


\section{Marco teórico}

Las redes sociales han cambiado la forma en que las personas interactúan entre sí y con el mundo que les rodea (Hawkins y Vel, 2013; Qualman, 2009; Safko, 2010). Como servicios basados en la web, las redes sociales son plataformas que combinan la tecnología Web 2.0 y el contenido generado por los usuarios (User-Generated Content) (He, Zha y Li, 2013; Kaplan y Haenlein, 2010;), permitiéndoles crear identidades, participar en conversaciones, generar y compartir contenidos, encontrar a otros usuarios, fomentar relaciones de muy diversa naturaleza, construir reputaciones, crear grupos de intereses diversos o unirse a estos (Kietzmann et al., 2011; Cvijikj, Spiegler y Michahelles, 2013. Ejemplos de redes sociales serían las salas de chat, blogs, sitios web de redes sociales, sitios web para compartir videos o imágenes, mundos sociales virtuales, proyectos colaborativos, comunidades comerciales o sitios web para almacenar y compartir enlaces de internet (Internet Bookmarks), entre otros (Mangold y Faulds, 2009; Kaplan y Haenlein, 2010; Castronovo y Huang, 2012).

Las organizaciones empresariales pueden usar las redes sociales para comunicarse con las audiencias de modo similar a como lo hacen con los medios tradicionales: para encontrar nuevos consumidores y fidelizarlos, mejorar su satisfacción, incrementar las ventas y los ingresos y, en consecuencia, construir una buena reputación de imagen de marca (Mandelli y Cantoni, 2010; He, Zha y Li, 2013; Yoshida et al., 2014); sin embargo, los consumidores también pueden usar estas plataformas para comunicarse entre sí (Mangold y Faulds, 2009), compartiendo de manera efectiva su propia experiencia, ya sea positiva o negativa, sobre las empresas, sus productos y marcas (Hudson et al., 2016), lo que transforma radicalmente el papel de estos consumidores-usuarios al convertirlos simultáneamente en emisores y receptores de contenido (Hanna, Rohm y Crittenden, 2011).

Las editoriales están adoptando las redes sociales para adaptarse a esta tendencia creciente con el fin de obtener valores comerciales como los indicados anteriormente (Culnan, McHugh y Zubillaga, 2010; He, Zha y Li, 2013; Kietzmann et al., 2011; Filo, Lock y Karg, 2015). De hecho, muchas de ellas han aprovechado el poder de las redes sociales en los últimos años para mantenerse en contacto con los lectores, solicitar comentarios sobre determinados títulos y ayudar a los editores a conocer los gustos e intereses de los lectores potenciales (Di Gangi, Wasko y Hooker, 2010, Nguyen et al., 2015).

La fuerza de las redes sociales ha sido capaz de redefinir el proceso de la comunicación en mercados cada vez más abiertos, relacionales y experienciales (Williams y Chinn, 2010; Zhu y Chen, 2015). Tradicionalmente, el modelo de comunicación se apoyaba en cuatro elementos: fuente, mensaje, canal y receptor (Berlo, 1960). Los procesos dentro de dicho modelo tradicional estaban relacionados con: codificación, decodificación, respuesta, retroalimentación y ruido (Rothwell, 2010). Con la aparición de las redes sociales, la naturaleza de la comunicación se ha hecho significativamente más compleja e inclusiva (García-Medina, Miquel-Segarra y Navarro-Beltrá, 2018).

En relación al tipo de mensaje adecuado en redes sociales, varios autores han subrayado que el contenido en forma de imagen suele ser el más efectivo (Hansson, Wrangmo y Søilen, 2013; Sabate et al., 2014; Kwok y Yu, 2013). Otros autores han encontrado que el contenido en línea efectivo debe ser entretenido e informativo (Cvijikj y Michahelles, 2013), interactivo y reactivo (Burton y Soboleva, 2011), humorístico y filantrópico (Zhang, Jansen y Chowdhury, 2011), y relevante y conversacional (Kwok y Yu, 2013).

Desde la literatura académica se ha reflexionado sobre el modelo de comunicación para incorporar los efectos derivados de las redes sociales (Castronovo y Huang, 2012; Hanna, Rohm y Crittenden, 2011; Hennig-Thurau et al., 2010; Islas, 2010; Mangold y Faulds, 2009). Mangold y Faulds (2009) conceptualizaron "el nuevo paradigma de la comunicación", enfatizando que el control de 
las empresas sobre el contenido, el tiempo y la frecuencia de la información se estaba "erosionando severamente". Tradicionalmente, una organización empresarial tenía un control considerable sobre cómo se percibía su imagen de marca a través de la gestión de su combinación promocional (promotional mix), incluidas las promociones de publicidad, relaciones públicas y ventas. Sin embargo, en el contexto del nuevo paradigma de la comunicación, los consumidores interactúan entre sí libremente para crear conversaciones sobre la empresa y su imagen de marca a través de las redes sociales. Mutter (2011) sostiene que el tamaño de las audiencias en redes sociales no es tan importante como su compromiso y lealtad. Por lo tanto, aunque las redes sociales pueden facilitar que una empresa se comunique de manera más eficiente, la incertidumbre asociada al impacto del mensaje promocional y a la falta de control del contenido generado por los consumidores puede resultar intimidante.

En 2010, Hennig-Thurau et al. desarrollaron el modelo o marco "pinball", que incorpora los efectos de las redes sociales en las relaciones con los consumidores: las empresas lanzan una "bola de marketing", las redes sociales actúan como topes que desvían la pelota de manera caótica e impredecible y los responsables de marketing emplean diversas tácticas para guiar la bola lanzada desde la empresa; sin embargo, la bola no siempre se dirige hacia donde se pretende, ya que el carácter disruptivo de las redes sociales hace que los efectos derivados de las actividades de marketing sobre estas sean: a) impredecibles, por la pérdida de control, b) omnipresentes, en la medida que las redes sociales impactan no solo sobre las acciones promocionales, sino también sobre otros aspectos relativos a las acciones de marketing como, por ejemplo, la gestión de las relaciones con los consumidores (Customer Relationship Management) o sobre la optimización de los motores de búsqueda (Search Engine Optimization) y c) cada vez más relevantes en las estrategias de comunicación empresarial (Castronovo y Huang, 2012).

En conclusión, desde la literatura académica se ha enfatizado que las empresas deben ejecutar y administrar correctamente: a) las actividades de marketing en redes sociales (Castronovo y Huang, 2012; Gao y Feng, 2016), b) las relaciones con los consumidores (Harrigan et al., 2017; Hennig-Thurau et al., 2010) y c) las discusiones en línea (Mangold y Faulds, 2009). Sin embargo, aunque estos modelos generalmente sugieren que las empresas deben utilizar las plataformas de redes sociales con habilidad e interactuar constantemente con los consumidores (Duffett, 2015), no existe un consenso sobre "cómo" pueden hacerlo de manera efectiva (Kohli, Suri y Kapoor, 2015) y es por ello que las investigaciones actuales se esfuerzan no solo por comprender el modo en que las organizaciones empresariales gestionan las redes sociales sino en identificar aquellas pautas estratégicas que resulten óptimas en dicha gestión (Popp y Woratschek, 2016).

Un aspecto esencial en las redes sociales es la medición de los KPIs (Key Performance Indicators) por parte de las organizaciones. Para ellos, se necesita la creación de un conjunto de indicadores y métricas únicos para medir el impacto de las campañas en los usuarios y determinar el éxito de los esfuerzos de la marca en la red social (Sánchez, Matos y Correia, 2019). Los KPIs son métricas empleadas para cuantificar objetivos que reflejan el rendimiento de una organización y son vehículos de comunicación vinculados a la estrategia de la organización (Geho y Dangelo, 2012).

A partir de la amplia diversidad de KPIs, el IAB (Internet Advertising Bureau) desarrolla un marco homogeneizador que agrupa los diferentes KPIs empleados en el análisis estratégico de las redes sociales, conocido como modelo PRGS y que será el empleado en el contexto de esta investigación. El modelo PRGS, de reciente desarrollo durante la segunda década del 2000, es heredero directo del modelo británico de las 4As (Awareness, Appreciation, Action and Advocacy). De los diversos marcos teóricos y métricas desarrolladas en los últimos años, el modelo PRGS ha ganado reconocimiento en su aplicación sobre muy diversos sectores de actividad económica (Information Research Management Association, 2018). Sin embargo, no se había aplicado al mundo editorial español. 


\section{Metodología}

Para llevar a cabo el análisis se ha tomado como base el modelo PRGS, propuesto por el IAB Spain Research (Interactive Advertising Bureau Spain, 2013). Este modelo ha sido utilizado en diversos estudios con resultados relevantes en diferentes áreas (Buhalis y Mamalakis, 2015; Oviedo-García et al., 2014; Pérez-García y Torres-Valdés, 2019, Rodríguez-Fernández et al., 2017; Sánchez-Amboage et al, 2019; Zorkociova y Vancova, 2016).

El análisis del modelo PRGS se fundamenta en cuatro variables para medir la intervención y la actividad de las marcas en redes sociales: presencia, respuesta, generación y sugerencia (Giraldo y Martínez, 2017). Los indicadores asociados a cada variable aparecen recogidos en la tabla 1, donde se especifica su descripción y medición.

Tabla 1. Variables e indicadores del modelo PRGS

\begin{tabular}{|c|c|c|c|c|}
\hline & Variable & & Indicadores & Descripción \\
\hline \multirow[t]{2}{*}{ MARCA } & \multirow[t]{2}{*}{ Presencia $(P)$} & \multirow[b]{2}{*}{$\begin{array}{l}\text { Su medida se relaciona con la } \\
\text { actividad de la marca y viene } \\
\text { dada por el número de fans } \\
\text { o seguidores y el número de } \\
\text { publicaciones que la marca } \\
\text { realiza en la página. Incluye } \\
\text { el tamaño de una comunidad } \\
\text { y el volumen de contenido } \\
\text { generado por la marca, es } \\
\text { decir la actividad de la marca } \\
\text { en los medios sociales. }\end{array}$} & P1. Comunidad. & $\begin{array}{l}\text { Número de seguidores } \\
\text { (fans). }\end{array}$ \\
\hline & & & P2. Contenido generado. & Número de publicaciones. \\
\hline \multirow[t]{3}{*}{ USUARIO } & Respuesta (R) & $\begin{array}{l}\text { Su medida se relaciona con la } \\
\text { actividad del usuario y viene } \\
\text { dada por el número de me } \\
\text { gusta que los mismos generan } \\
\text { ante las publicaciones de la } \\
\text { marca }\end{array}$ & R. Reacciones. & $\begin{array}{l}\text { Número de reacciones a } \\
\text { las publicaciones. }\end{array}$ \\
\hline & Generación (G) & $\begin{array}{l}\text { Su medida se relaciona con } \\
\text { la actividad del usuario y } \\
\text { viene dada por el número } \\
\text { de comentarios que los } \\
\text { mismos generan ante las } \\
\text { publicaciones de la marca. }\end{array}$ & $\begin{array}{l}\text { G. Contenido generado } \\
\text { usuario. }\end{array}$ & $\begin{array}{l}\text { Viene dada por el } \\
\text { número de comentarios } \\
\text { de los usuarios que los } \\
\text { mismos generan ante las } \\
\text { publicaciones. }\end{array}$ \\
\hline & Sugerencia (S) & $\begin{array}{l}\text { Su medida se relaciona con } \\
\text { la actividad del usuario y } \\
\text { viene dada por el número } \\
\text { de comparticiones que los } \\
\text { mismos generan ante las } \\
\text { publicaciones de la marca. }\end{array}$ & S. Recomendaciones. & $\begin{array}{l}\text { Viene dada por el número } \\
\text { de comparticiones o } \\
\text { recomendaciones de } \\
\text { los usuarios que los } \\
\text { mismos generan ante las } \\
\text { publicaciones. }\end{array}$ \\
\hline
\end{tabular}

Fuente: elaboración propia a partir del IAB (2013).

Tomando como punto de partida las variables e indicadores del modelo PRGS, es posible formular una matriz que determine la naturaleza absoluta o relativa del indicador adoptado para cada variable (ver tabla 2). Así, la variable presencia (P) se mide en valor absoluto, al considerar que la actividad que realice la marca en su página será independiente del número de fans que posea. Por el contrario, las variables respuesta $(R)$, generación $(G)$ y sugerencia $(S)$ se miden en valor relativo, en función del número de fans de la página (comunidad), ya que la actividad que el usuario realice en la página dependerá o estará condicionada por dicho número (Giraldo y Martínez, 2017). 
Tabla 2. Matriz del modelo PRGS

\begin{tabular}{|l|l|}
\hline $\begin{array}{c}\text { Presencia } \\
\text { P1=número de fans }\end{array}$ & $\begin{array}{r}\text { Respuesta } \\
\text { R2=Me gusta/número de fans }\end{array}$ \\
\hline $\begin{array}{l}\text { Generación } \\
\text { G=Comentarios/número dans }\end{array}$ & Sugerencia \\
\hline
\end{tabular}

Fuente: elaboración propia a partir de Giraldo y Martínez (2017).

Por otra parte, hay que tener presente que, dependiendo de las redes sociales analizadas, la denominación atribuida a los valores de análisis puede variar, tal y como se indican en tabla 3.

Tabla 3. Valores de análisis en el modelo PRGS

\begin{tabular}{|c|c|c|c|c|}
\hline & Variable & Facebook & Twitter & Instagram \\
\hline \multirow[t]{2}{*}{ MARCA } & \multirow[t]{2}{*}{ Presencia } & Fans & Seguidores & Seguidores \\
\hline & & Posts & Tuits & Publicaciones \\
\hline \multirow[t]{3}{*}{ USUARIO } & Respuesta & $\begin{array}{l}\text { Reacciones (me gusta, me encanta, } \\
\text { me entristece...)/fans }\end{array}$ & Me gusta/fans & Me gusta/fans \\
\hline & Generación & Comentarios/fans & Comentarios/fans & Comentarios/fans \\
\hline & Sugerencia & Contenido compartido/fans & Retwittear contenido/fans & \\
\hline
\end{tabular}

Fuente: elaboración propia.

Con el fin de medir el impacto de cada variable en función de la comunidad de cada una de las tres redes sociales estudiadas (Facebook, Twitter e Instagram), se proponen las siguientes ratios indicadas en la tabla 4. Para una mejor interpretación de los resultados, las variables respuesta (R), generación $(G)$ y sugerencia $(S)$ se han unido para obtener, en una sola variable, una ratio denominada engagement (E) que agrega el total de interacciones realizadas por los usuarios de una red (Buhalis y Mamalakis, 2015).

Tabla 4. Medidas y ratios del modelo PRGS

\begin{tabular}{|c|c|c|c|}
\hline Variable & Indicador & Descripción & Fórmula \\
\hline \multirow[t]{3}{*}{ Presencia } & Comunidad & $\begin{array}{l}\text { Número de seguidores o fans (f) de la } \\
\text { red social. }\end{array}$ & \\
\hline & Actividad & $\begin{array}{l}\text { Número de publicaciones o } \\
\text { contenidos generados (c). }\end{array}$ & \\
\hline & Ratio de actividad & $\begin{array}{l}\text { Cantidad de contenidos que generan } \\
\text { las marcas por cada } 100 \text { usuarios de } \\
\text { su comunidad. }\end{array}$ & $\begin{array}{l}\text { Contenido generado } / \\
\text { Comunidad }=\mathrm{P} 2 / \mathrm{P} 1=\mathrm{m} / \mathrm{n}\end{array}$ \\
\hline $\begin{array}{l}\text { Engagement } \\
\text { (Respuesta, } \\
\text { Generación y } \\
\text { Sugerencia) }\end{array}$ & Ratio de engagement & $\begin{array}{l}\text { Cantidad de interacciones que se } \\
\text { realizan con las marcas en los medios } \\
\text { sociales por cada } 100 \text { usuarios }\end{array}$ & $\begin{array}{l}\text { (reacciones + contenido } \\
\text { generado usuario comentarios + } \\
\text { recomendaciones) / Comunidad } \\
=\mathrm{R}+\mathrm{G}+\mathrm{S} / \mathrm{P} 1\end{array}$ \\
\hline
\end{tabular}

Fuente: elaboración propia.

La investigación desarrollada entre junio de 2018 y mayo de 2019 estudia la actividad de las editoriales seleccionadas en sus respectivas cuentas oficiales de Facebook, Twitter e Instagram a través de la herramienta online Fanpage Karma. Esta herramienta en línea se ha utilizado en varios estudios de investigación para analizar y monitorear las redes sociales (Jayasingh y Venkatesh, 2015; Huertas y Marine-Roig, 2016; Wozniak et al., 2017; Sánchez, Matos y Correia, 2019). 
Desarrollada por Nicolas Graf von Kanitz y Stephan Eyl, hace su aparición en 2012. Se trata de una herramienta online de monitorización y análisis de redes sociales tales como Facebook, Twitter, Instagram o YouTube, entre otras, que permite aplicarla a diversos usos como, por ejemplo: a) evaluación de la actividad de las propias redes sociales de una organización con objeto de mejorarlas en el contexto de sus campañas de marketing digital, b) evaluación de la actividad de las redes sociales de los principales competidores, de cara a implementar una estrategia sostenida en el benchmarking, y c) evaluación e interpretación de las redes sociales de un conjunto de organizaciones con propósito de comprender la implantación e impacto de las mismas dentro de un sector de actividad. Para ello, ofrece múltiples posibilidades de análisis de perfiles y amplias comparativas de páginas a través de información cuantitativa precisa y visualizaciones gráficas que facilitan la interpretación de los datos obtenidos.

\subsection{Selección de la muestra}

Para llevar a cabo el estudio se seleccionaron inicialmente las 25 principales editoriales españolas especializadas en novela, según la Panorámica de la Edición de Libros, que anualmente publica el Observatorio de la Lectura y el Libro, dependiente del Ministerio de Cultura. Muchas de ellas pertenecen a alguno de los tres grandes grupos editoriales de referencia: Penguin Random House, Planeta y Anaya.

La Panorámica de la edición española de libros se comenzó a publicar en 1988 y es un profundo estudio estadístico de la producción editorial española que combina datos que proceden de la Dirección General del Libro, Archivos y Bibliotecas, de la Agencia Española del ISBN (International Standard Book Number) y del Instituto Nacional de Estadística (INE). Ofrece una radiografía de los distintos aspectos implicados en la edición y constituye una fuente de información indispensable para conocer, analizar y valorar la realidad del sector del libro en España. Actualmente, se publica por el Observatorio de la Lectura y el Libro, organismo perteneciente al Ministerio Cultura y Deporte de España, y cuyo propósito es el de analizar permanentemente la situación del libro, la lectura y las bibliotecas en su conjunto. En el presente estudio se ha considerado el número de publicaciones editadas por los agentes editores españoles que han adquirido ISBNs y que los han registrado en la materia de literatura, correspondiente a la materia 23 mostrada en el listado ofrecido por la Panorámica de la edición española.

La recogida de la información se llevó a cabo en dos fases: en primer lugar, se consultaron las páginas web de cada una de las editoriales seleccionadas y, en segundo lugar, una vez establecida su posición por cuota de mercado según el número de títulos inscritos en el ISBN, se procede a analizar su presencia y actividad en Facebook, Twitter e Instagram.

En la tabla 5 se muestra el ranking de las 25 primeras editoriales en publicación de literatura, conforme al número de ISBNs registrados oficialmente en 2017 así como su presencia en las redes sociales consideradas para este estudio (Facebook, Twitter e Instragram). Las páginas web de cada una de las editoriales, junto a sus respectivos espacios en las redes sociales consideradas en este estudio, muestran un perfil público oficial que las representa (Chu, 2011; Zaglia, 2013) y que proporciona información a los usuarios (Chatterjee, 2011). 
Tabla 5. Ranking de las 25 primeras editoriales en publicación de literatura según el número de ISBNs inscritos en 2017 y su participación en redes sociales

\begin{tabular}{|c|c|c|c|c|c|c|c|}
\hline $\begin{array}{l}\text { N. }{ }^{\circ} \text { de } \\
\text { orden }\end{array}$ & $\begin{array}{l}\text { Nombre de } \\
\text { la editorial }\end{array}$ & $\begin{array}{l}\text { Número } \\
\text { de } \\
\text { títulos } \\
\text { inscritos } \\
\text { ISBN }\end{array}$ & \begin{tabular}{|l}
$\%$ \\
respecto \\
del total \\
de títulos \\
en la \\
materia
\end{tabular} & Web & Facebook & Twitter & Instagram \\
\hline 1 & $\begin{array}{l}\text { Editorial } \\
\text { Círculo } \\
\text { Rojo }\end{array}$ & 1432 & 6,6 & www.editorialcirculorojo.com & @EditorialCirculoRojo & @Edicirculorojo & @editorialcirculorojo \\
\hline 2 & $\begin{array}{l}\text { Harlequín } \\
\text { Ibérica }\end{array}$ & 1127 & 5,2 & $\begin{array}{l}\text { www.harpercollinsiberica.com/ } \\
\text { harlequin }\end{array}$ & @Harlequinlberica & @HARLEQUINLibros & @harlequinibericalibros) \\
\hline 3 & $\begin{array}{l}\text { Editorial } \\
\text { Planeta, } \\
\text { S. A. }\end{array}$ & 860 & 4,0 & $\begin{array}{l}\text { www.planetadelibros.com/ } \\
\text { editorial/editorial-planeta/8 }\end{array}$ & @ Planetadelibros & @Planetadelibros & @planetadelibros \\
\hline 4 & $\begin{array}{l}\text { Ediciones } \\
\text { Corín } \\
\text { Tellado }\end{array}$ & 645 & 3,0 & $\begin{array}{l}\text { www.planetadelibros.com/ } \\
\text { editorial/ediciones-corin- } \\
\text { tellado/522 }\end{array}$ & @EDCorinTellado & & \\
\hline 5 & $\begin{array}{l}\text { Bubok } \\
\text { Publishing, } \\
\text { S. L. }\end{array}$ & 369 & 1,7 & www.bubok.es & @bubok & @bubok & @bubok_es \\
\hline 6 & $\begin{array}{l}\text { Gerüst } \\
\text { Creaciones, } \\
\text { S. L. }\end{array}$ & 284 & 1,3 & & & & \\
\hline 7 & \begin{tabular}{|l|} 
Editorial \\
Seix Barral
\end{tabular} & 267 & 1,2 & $\begin{array}{l}\text { www.planetadelibros.com/ } \\
\text { editorial/seix-barral/9 }\end{array}$ & @seixbarral & @ Seix_Barral & @seix_barral \\
\hline 8 & $\begin{array}{l}\text { Ediciones } \\
\text { Destino }\end{array}$ & 257 & 1,2 & $\begin{array}{l}\text { www.planetadelibros.com/ } \\
\text { editorial/ediciones-destino/7 }\end{array}$ & @edicionesdestino & @EdDestino & \\
\hline 9 & $\begin{array}{l}\text { Columna } \\
\text { CAT }\end{array}$ & 244 & 1,1 & $\begin{array}{l}\text { www.grup62.cat/editorial/ } \\
\text { columna-edicions/83 }\end{array}$ & @ Columnaedicions & @columnaedicions & @ columnaedicions \\
\hline 10 & $\begin{array}{l}\text { Alianza } \\
\text { Editorial }\end{array}$ & 242 & 1,1 & www.alianzaeditorial.es & @alianzaedit & @ alianza_ed & @alianzaeditorial \\
\hline 11 & $\begin{array}{l}\text { Ediciones } \\
\text { Oblicuas }\end{array}$ & 181 & 0,8 & www.edicionesoblicuas.com & @ edicionesoblicuas & @EdOblicuas & \\
\hline 12 & Edicions 62 & 177 & 0,8 & $\begin{array}{l}\text { www.grup62.cat/editorial/ } \\
\text { edicions-62/64 }\end{array}$ & @Edicions62 & @Ed_62 & @edicions_62 \\
\hline 13 & $\begin{array}{l}\text { Punto de } \\
\text { Lectura }\end{array}$ & 171 & 0,8 & $\begin{array}{l}\text { www.megustaleer.com/ } \\
\text { editoriales/punto-de-lectura/PL }\end{array}$ & @puntodelectura & & \\
\hline 14 & Siruela & 169 & 0,8 & www.siruela.com & @Edicionessiruela & @edicionesiruela & @siruelaediciones \\
\hline 15 & $\begin{array}{l}\text { B de Books } \\
\text { (Ediciones } \\
\text { B) }\end{array}$ & 168 & 0,8 & $\begin{array}{l}\text { www.megustaleer.com/ } \\
\text { editoriales/b-de-books/BK }\end{array}$ & & & \\
\hline 16 & $\begin{array}{l}\text { Ediciones } \\
\text { Minotauro }\end{array}$ & 165 & 0,8 & $\begin{array}{l}\text { www.planetadelibros.com/ } \\
\text { editorial/minotauro/21 }\end{array}$ & @EdicionesMinotauro & @minotaurolibros & @edicionesminotauro) \\
\hline 17 & $\begin{array}{l}\text { Vivelibro } \\
\text { (sello } \\
\text { Zasbook, } \\
\text { S. L.) }\end{array}$ & 161 & 0,7 & www.vivelibro.com & @vivelibro.editorial & @viveLibro_ed & @vivelibro_ed \\
\hline 18 & Labutxaca & 151 & 0,7 & $\begin{array}{l}\text { www.grup62.cat/editorial/ } \\
\text { labutxaca/66 }\end{array}$ & @labutxaca & @labutxaca & @labutxaca \\
\hline 19 & $\begin{array}{l}\text { Literatura } \\
\text { Random } \\
\text { House } \\
\end{array}$ & 148 & 0,7 & $\begin{array}{l}\text { www.megustaleer.com/ } \\
\text { editoriales/literatura-random- } \\
\text { house/MD }\end{array}$ & @LiteraturaRandomHouse & @LitRandomHouse & @litrandomhouse \\
\hline 20 & Caligrama & 142 & 0,7 & www.caligramaeditorial.com & @CaligramaEditorial & @caligramaeditor & @caligramaeditorial \\
\hline 21 & $\begin{array}{l}\text { Ediciones } \\
\text { Atlantis }\end{array}$ & 142 & 0,7 & www.edicionesatlantis.com & @ edicionesatlantis & @EdAtlantis & @edicionesatlantis \\
\hline 22 & $\begin{array}{l}\text { Letrame, } \\
\text { S. L. }\end{array}$ & 140 & 0,6 & www.letrame.com/ & @ LetrameGrupoEditorial & & \\
\hline 23 & $\begin{array}{l}\text { Espasa } \\
\text { Libros, } \\
\text { S. L. }\end{array}$ & 129 & 0,6 & $\begin{array}{l}\text { www.planetadelibros.com/ } \\
\text { editorial/espasa/5 }\end{array}$ & @editorialespasa/ & @editorialespasa & @espasaeditorial \\
\hline 24 & $\begin{array}{l}\text { Punto Rojo } \\
\text { Libros, } \\
\text { S. L. }\end{array}$ & 127 & 0,6 & puntorojolibros.com/ & @ puntorojolibros & @puntorojolibros & \\
\hline \multirow[t]{2}{*}{25} & $\begin{array}{l}\text { Ediciones } \\
\text { Amargord }\end{array}$ & 121 & 0,6 & $\begin{array}{l}\text { http://www.amargordediciones. } \\
\text { com/ }\end{array}$ & "editorial.amargord/ & & \\
\hline & Total & 8019 & 37,0 & & & & \\
\hline
\end{tabular}

Fuente: Panorámica de la edición de libros (2018) y elaboración propia.

Una vez realizado el análisis de búsqueda directa a través de cada una de las principales redes sociales, se procede a descartar de la muestra aquellas editoriales que: a) son de autopublicación, como Círculo Rojo, Bubok Publishing, Ediciones Oblicuas, Vivelibro, Caligrama, Ediciones 
Atlantis, Letrame y Punto Rojo Libros; b) publican en otros idiomas distintos al español, como es el caso de Columna CAT, Edicions 62 y Labutxaca; y c) no tienen página web o no tienen cuenta en Instagram como empresa a fecha del estudio realizado, como es el caso Ediciones Corín Tellado, Gerüst Creaciones, Destino, Punto de Lectura, B de Books, y Ediciones Amargord.

En la autopublicación el autor asume todos los gastos de edición, desde la producción hasta la distribución, pasando por el diseño y la maquetación. En los últimos años, importantes editoriales y librerías apuestan firmemente por hacerse un espacio en el mundo de la autopublicación, como una línea más de su negocio. Las plataformas de autopublicación vinculadas a los sellos editoriales podrían redefinir los límites, hasta ahora establecidos, entre escritores y aspirantes a escritores (autores indies) en el mundo del libro. El número de autores que, cansados de esperar una respuesta editorial o que por desconocimiento del mercado editorial no llegan a ser leídos por un editor, deciden optar por una editorial de autopublicación. En España Bubok es una plataforma pionera de autopublicación online que permite editar, publicar y vender libros bajo demanda, tanto en formato papel como digital. La editorial Círculo Rojo es la editorial líder en España en número de libros publicados según el registro del ISBN.

La existencia de otras lenguas oficiales en el Estado español -como el Catalán, Euskera y Gallego- y no oficiales -como el Asturiano o el Valenciano- ha generado la proliferación de sellos editoriales que publican en esas lenguas, lo que ha provocado la generación de un tejido editorial importante y en la que solo hay sellos que editan en esos idiomas.

Tras el filtrado, la muestra de editoriales a analizar queda reducida a ocho, tal y como se muestra en la tabla 6.

Tabla 6. Muestra de editoriales a analizar

\begin{tabular}{|c|c|c|c|c|c|}
\hline $\begin{array}{l}\mathrm{N} . \\
\text { orden }\end{array}$ & $\begin{array}{l}\text { Nombre de } \\
\text { la editorial }\end{array}$ & Web & Facebook & Twitter & Instagram \\
\hline 1 & $\begin{array}{l}\text { Harlequín } \\
\text { lbérica }\end{array}$ & $\begin{array}{l}\text { www. } \\
\text { harpercollinsiberica. } \\
\text { com/harlequin }\end{array}$ & $@$ Harlequinlberica & @HARLEQUINLibros & @harlequinibericalibros \\
\hline 2 & $\begin{array}{l}\text { Editorial } \\
\text { Planeta }\end{array}$ & $\begin{array}{l}\text { www.planetadelibros. } \\
\text { com/editorial/ } \\
\text { editorial-planeta/8 }\end{array}$ & $@$ Planetadelibros & @Planetadelibros & @planetadelibros \\
\hline 3 & $\begin{array}{l}\text { Editorial } \\
\text { Seix Barral }\end{array}$ & $\begin{array}{l}\text { www.planetadelibros. } \\
\text { com/editorial/seix- } \\
\text { barral/9 }\end{array}$ & @seixbarral & @Seix_Barral & @seix_barral \\
\hline 4 & $\begin{array}{l}\text { Alianza } \\
\text { Editorial }\end{array}$ & $\begin{array}{l}\text { www.alianzaeditorial. } \\
\text { es }\end{array}$ & @alianzaedit & @alianza_ed & @alianzaeditorial \\
\hline 5 & Siruela & www.siruela.com & @Edicionessiruela & @edicionesiruela & @siruelaediciones \\
\hline 6 & $\begin{array}{l}\text { Ediciones } \\
\text { Minotauro }\end{array}$ & $\begin{array}{l}\text { www.planetadelibros. } \\
\text { com/editorial/ } \\
\text { minotauro/21 }\end{array}$ & @EdicionesMinotauro & @minotaurolibros & @edicionesminotauro \\
\hline 7 & $\begin{array}{l}\text { Literatura } \\
\text { Random } \\
\text { House }\end{array}$ & $\begin{array}{l}\text { www.megustaleer. } \\
\text { com/editoriales/ } \\
\text { literatura-random- } \\
\text { house/MD }\end{array}$ & @LiteraturaRandomHouse & @LitRandomHouse & @litrandomhouse \\
\hline 8 & $\begin{array}{l}\text { Espasa } \\
\text { Libros }\end{array}$ & $\begin{array}{l}\text { www.planetadelibros. } \\
\text { com/editorial/ } \\
\text { espasa/5 }\end{array}$ & @editorialespasa & @editorialespasa & @espasaeditorial \\
\hline
\end{tabular}

Fuente: elaboración propia.

Una vez fijada la muestra, se exponen los resultados derivados del análisis efectuado, organizados en función de las variables e indicadores del modelo PRGS expuesto anteriormente. 


\section{Resultados}

En este apartado se muestran los resultados obtenidos en el análisis de la intervención y la actividad en las redes sociales de las editoriales analizadas durante el periodo de junio de 2018 a mayo 2019 teniendo en cuenta las variables presencia y engagement para cada una de las redes sociales: Facebook, Twitter e Instagram. Dicho análisis ha empleado la herramienta online Fanpage Karma que permite la monitorización de redes sociales y que ya ha sido aplicada en diversas investigaciones (Huertas y Marine-Roig, 2016; Jayasingh y Venkatesh, 2015; Wozniak et al., 2017).

\subsection{Análisis de la variable presencia}

La presencia se relaciona con la actividad de la marca y viene dada por: a) la comunidad, es decir, el número de fans o seguidores (P1), y b) el contenido generado, esto es, el número de publicaciones que la marca realiza (P2). Finalmente, la ratio de actividad combina los dos indicadores anteriores para determinar la intensidad en la generación de contenidos por parte de las editoriales analizadas por cada cien usuarios de la red estudiada.

\subsubsection{Presencia en Facebook}

El indicador P1 señala claramente a la Editorial Planeta y a Alianza Editorial como aquellas con mayor número de fans en Facebook, al tiempo que muestra cómo en la Editorial Planeta, P1 tiene una tendencia creciente frente a un cierto estancamiento de las demás editoriales analizadas (ver gráfico 1).

Gráfico 1. Evolución de los fans en Facebook (junio 2018 a mayo 2019)

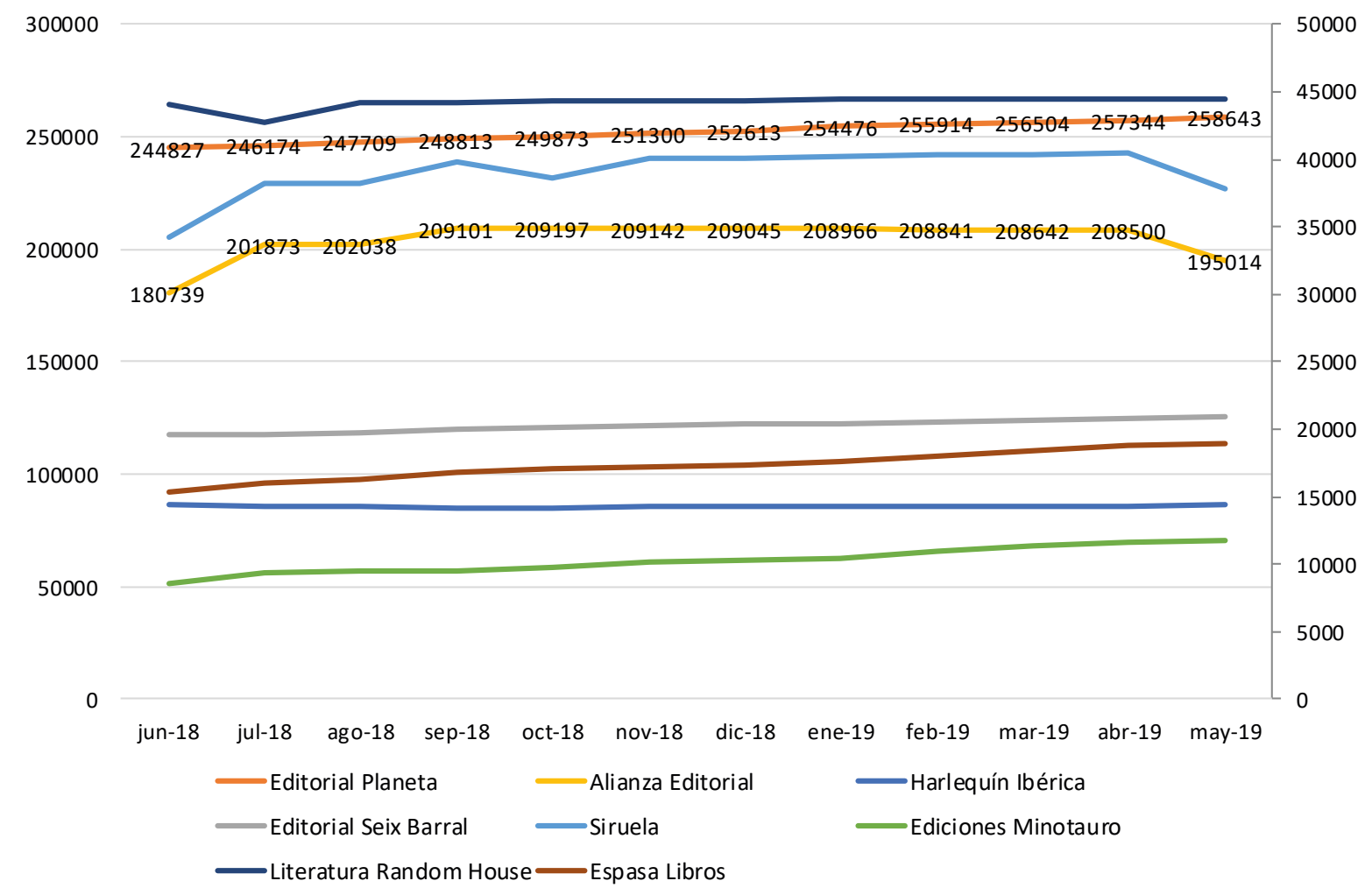

Fuente: elaboración propia a partir de Fanpage Karma. 
El indicador P2 señala a Alianza Editorial y a Literatura Random House como las dos editoriales generadoras de mayor número de posts en Facebook, seguidas de cerca por la Editorial Planeta (ver gráfico 2).

Gráfico 2. Evolución de los posts en Facebook (junio 2018 a mayo 2019)

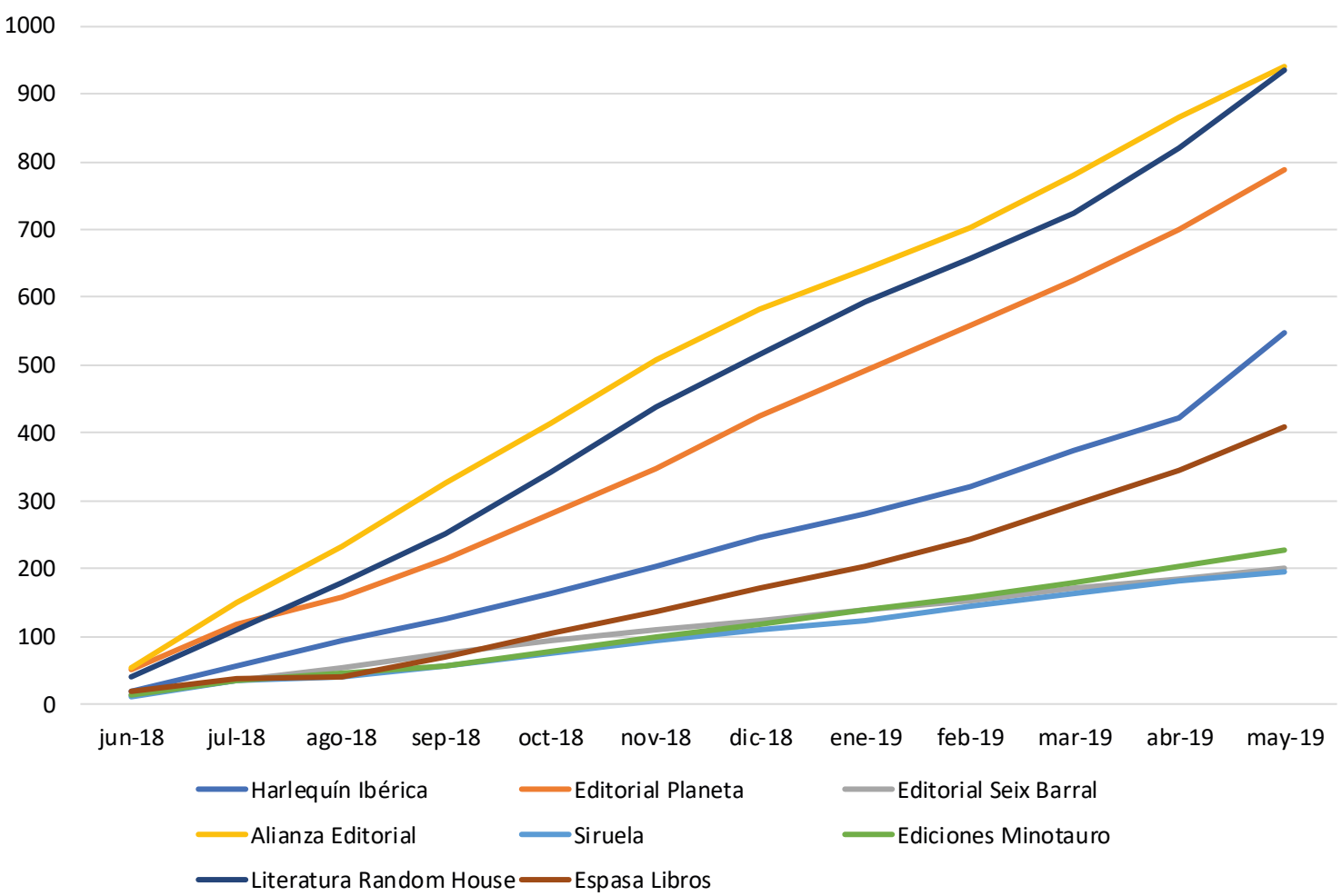

Fuente: elaboración propia a partir de Fanpage Karma.

La ratio de actividad definida como la cantidad de contenidos que generan las marcas por cada 100 usuarios de su comunidad nos muestra (ver tabla 7) que Harlequín Ibérica $(1,67 \%)$, sería la que más contenidos genera en relación a sus fans. En el otro extremo, la que menos contenidos genera en relación a sus fans resulta ser la Editorial Planeta $(0,16 \%)$.

Tabla 7. Ratio de actividad en Facebook

\begin{tabular}{|l|c|c|c|}
\hline Editorial & Fans & Posts & Ratio de actividad = (posts/fans) ${ }^{\star 100}$ \\
\hline Harlequín Ibérica & 14.270 & 238 & $1,67 \%$ \\
\hline Editorial Planeta & 252.016 & 396 & $0,16 \%$ \\
\hline Editorial Seix Barral & 20.231 & 113 & $0,56 \%$ \\
\hline Alianza Editorial & 204.258 & 517 & $0,25 \%$ \\
\hline Siruela & 39.026 & 103 & $0,26 \%$ \\
\hline Ediciones Minotauro & 10.255 & 113 & $1,10 \%$ \\
\hline Literatura Random House & 44.191 & 467 & $1,06 \%$ \\
\hline Espasa Libros & 17.322 & 173 & $1,00 \%$ \\
\hline
\end{tabular}

Fuente: elaboración propia.

\subsubsection{Presencia en Twitter}

El indicador P1 identifica claramente a la Editorial Planeta y a Alianza Editorial como aquellas con mayor número de seguidores en Twitter, a una distancia considerable de las restantes editoriales analizadas y la tendencia de su crecimiento en todas ellas está relativamente estancada (ver gráfico 3). 
Gráfico 3. Evolución de los seguidores en Twitter (junio 2018 a mayo 2019)

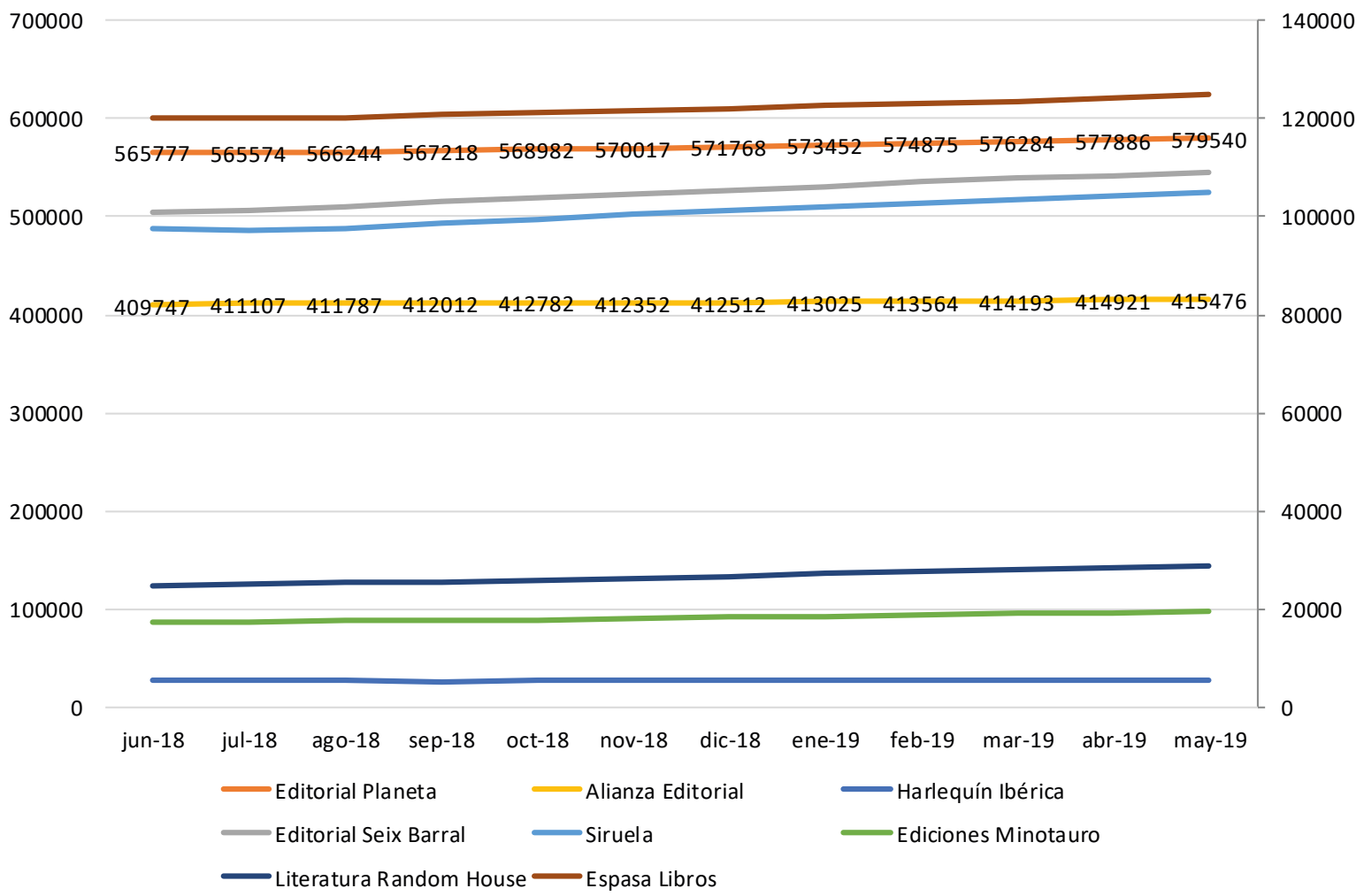

Fuente: elaboración propia a partir de Fanpage Karma.

Gráfico 4. Evolución de los tuits en Twitter (junio 2018 a mayo 2019)

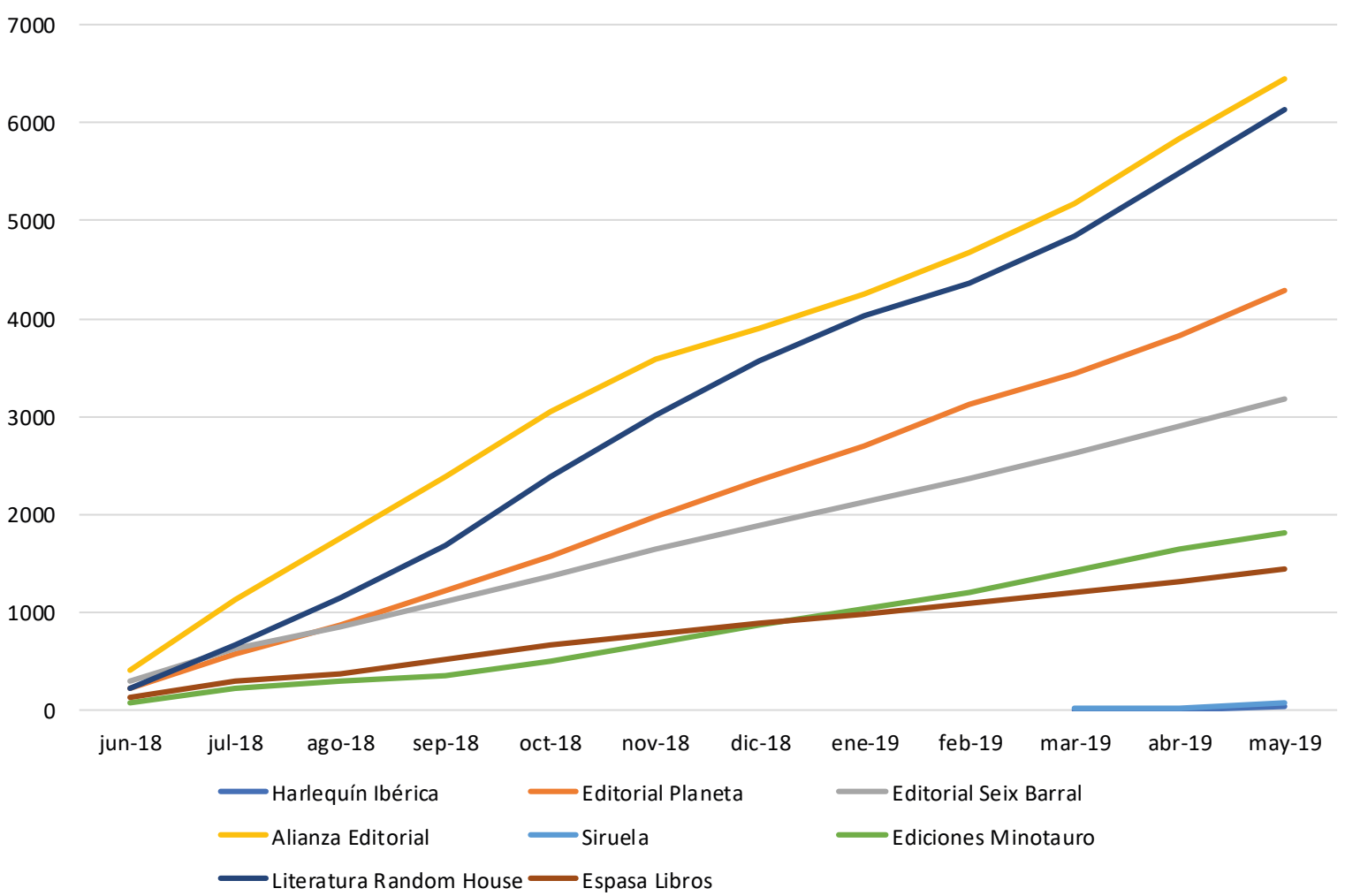

Fuente: elaboración propia a partir de Fanpage Karma. 
El indicador P2 señala a Alianza Editorial y a Literatura Random House como las dos editoriales generadoras de mayor número de tuits en Twitter, seguidas de cerca por la Editorial Planeta y la Editorial Seix Barral. Como se observa, se trata de un resultado bastante similar al obtenido en el análisis de Facebook, salvo por la significativa actividad de Seix Barral, los casos particulares de Siruela y Harlequín Ibérica, cuyas respectivas P2 son prácticamente inexistentes en esta red social (ver gráfico 4).

La ratio de actividad de Random House (141\%) en Twitter se encuentra a una gran distancia respecto de las demás ratios de las restantes editoriales estudiadas, incluida la editorial Minotauro $(55,34 \%)$, que se sitúa en el segundo puesto por ratio de actividad. En el otro extremo, Siruela $(0,08 \%)$ y Harlequín Ibérica $(0,63 \%)$ apenas tienen una ratio de actividad significativa en Twitter (ver tabla 8 ).

Tabla 8. Ratio de actividad en Twitter

\begin{tabular}{|l|r|r|r|}
\hline Editoriales & Seguidores & \multicolumn{1}{|c|}{ Tuits } & Ratio de actividad=(Tuits/seguidores) ${ }^{* 100}$ \\
\hline Harlequín Ibérica & 5.517 & 35 & $0,63 \%$ \\
\hline Editorial Planeta & 571.468 & 26.132 & $4,57 \%$ \\
\hline Editorial Seix Barral & 104.982 & 20.947 & $19,95 \%$ \\
\hline Alianza Editorial & 412.790 & 42.568 & $10,31 \%$ \\
\hline Siruela & 100.795 & 81 & $0,08 \%$ \\
\hline Ediciones Minotauro & 18.246 & 10.097 & $55,34 \%$ \\
\hline Literatura Random House & 26.625 & 37.539 & $141,00 \%$ \\
\hline Espasa Libros & 122.081 & 9.630 & $7,89 \%$ \\
\hline
\end{tabular}

Fuente: elaboración propia a partir de Fanpage Karma.

\subsubsection{Presencia en Instagram}

El indicador P1 apunta claramente a la Editorial Planeta como la de mayor número de seguidores en Instagram, a una distancia importante de Espasa Libros, la segunda en el ranking. El resto de las editoriales tienen un valor P1 muy bajo en comparación con las dos anteriores (ver gráfico 5). Es preciso comentar que los datos apenas significativos del indicador P1 en los casos de Harlequín Ibérica y Siruela son la consecuencia de la reciente creación de sus perfiles oficiales en esta red social (septiembre de 2018 y marzo de 2019, respectivamente).

Gráfico 5. Evolución de los seguidores en Instagram (junio 2018 a mayo 2019)

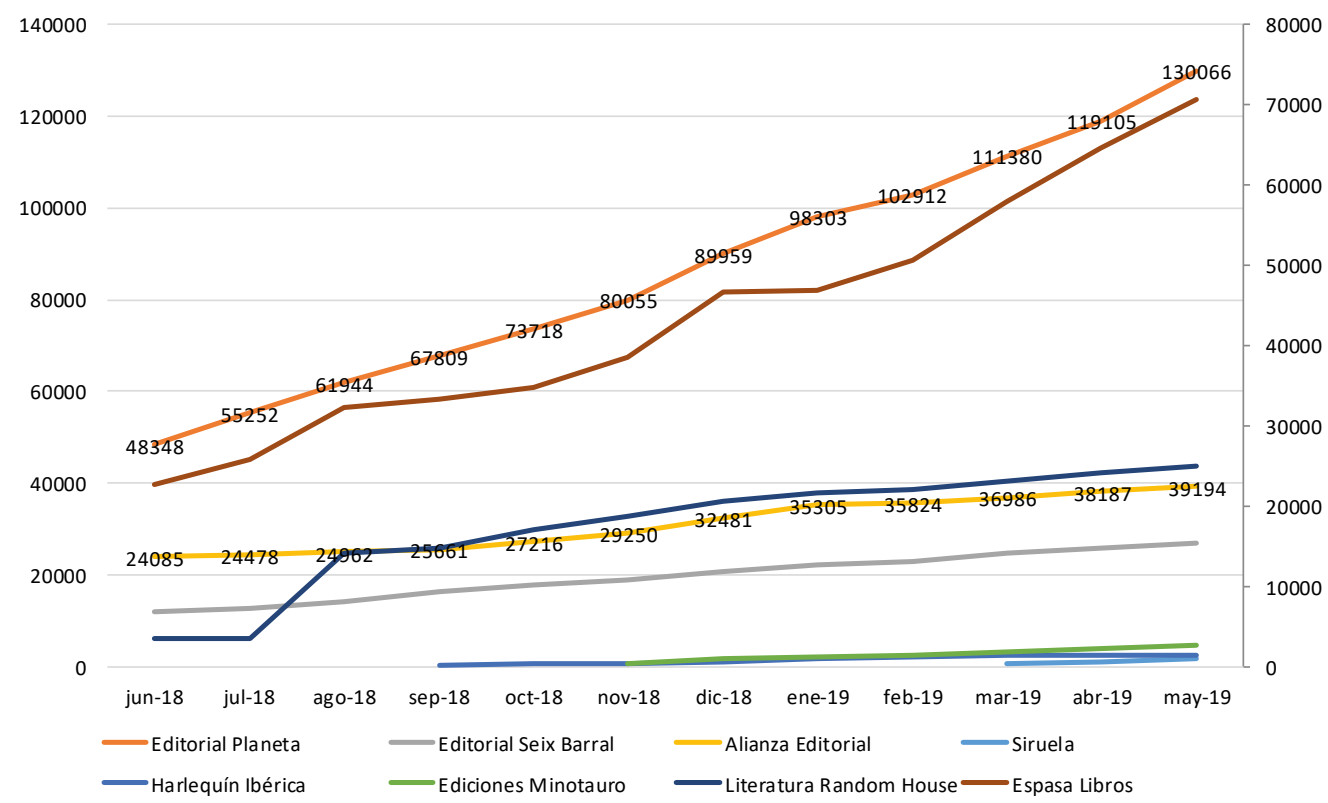

Fuente: elaboración propia a partir de Fanpage Karma. 
El indicador P2 muestra cómo la Editorial Planeta y Harlequín Ibérica lideran la generación de publicaciones en Instagram, lo que resulta llamativo dada la entrada tardía de Harlequín Ibérica, cuyo empuje y apuesta por el desarrollo de su marca en esta red social contrasta con una entrada mucho menos vigorosa en el caso de Siruela (ver gráfico 6).

Gráfico 6. Evolución de las publicaciones en Instagram (junio 2018 a mayo 2019)

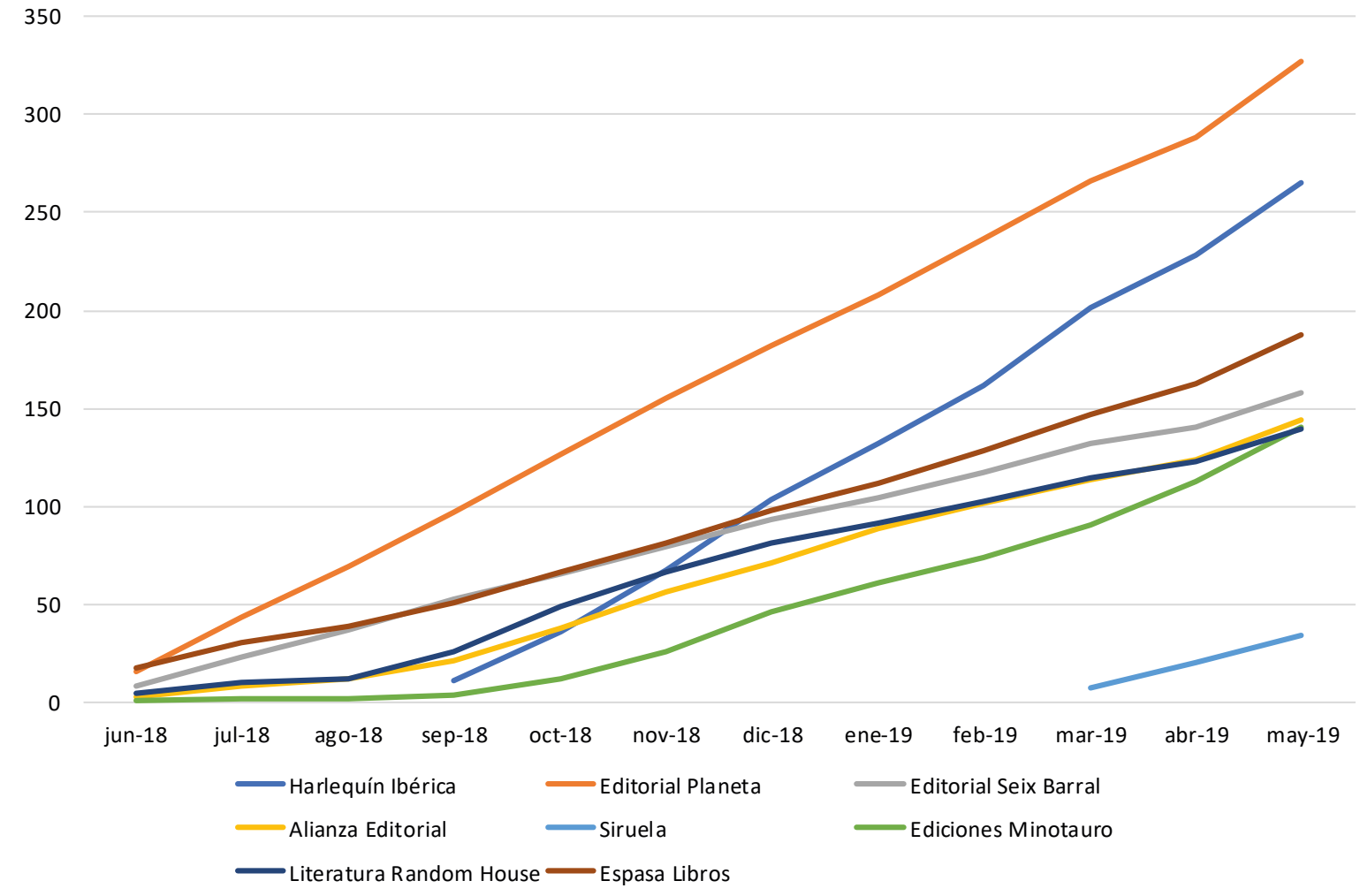

Fuente: elaboración propia a partir de Fanpage Karma.

La ratio de actividad de Harlequín Ibérica (14,89\%) en Instagram es bastante más elevada que las demás ratios del resto de editoriales analizadas, incluida la editorial Minotauro (5,33\%), que se sitúa en el segundo puesto para Instagram. En el otro extremo, Editorial Planeta $(0,19 \%)$ y Espasa Libros $(0,21 \%)$ apenas tienen una ratio de actividad significativa en Instagram (ver tabla 9).

Tabla 9. Ratio de actividad en Instagram

\begin{tabular}{|l|r|r|r|}
\hline Editoriales & Seguidores & Publicaciones & Ratio de actividad = (Publicaciones/seguidores) $)^{*} \mathbf{1 0 0}$ \\
\hline Harlequín Ibérica & 672 & 100 & $14,89 \%$ \\
\hline Editorial Planeta & 86.571 & 168 & $0,19 \%$ \\
\hline Editorial Seix Barral & 19.646 & 84 & $0,43 \%$ \\
\hline Alianza Editorial & 31.137 & 65 & $0,21 \%$ \\
\hline Siruela & 291 & 5 & $1,72 \%$ \\
\hline Ediciones Minotauro & 882 & 47 & $5,33 \%$ \\
\hline Literatura Random House & 17.065 & 68 & $0,40 \%$ \\
\hline Espasa Libros & 43.771 & 93 & $0,21 \%$ \\
\hline
\end{tabular}

Fuente: elaboración propia a partir de Fanpage Karma. 


\subsubsection{Análisis del ranking de presencia}

Tomando como referencia el indicador P1 (fans y seguidores), se observa que la Editorial Planeta lidera la presencia en las tres redes sociales analizadas, con 252.016 fans en Facebook, 571.468 en Twitter y 86.571 en Instagram y sólo pierde el liderazgo en favor de Alianza Editorial en cuanto al indicador P2 -relativo a la generación de contenidos-, en dos de las tres redes, ya que en Instagram la Editorial Planeta sigue manteniendo su liderazgo con 168 publicaciones de media en el período analizado (ver tabla 10).

Tabla 10. Ranking de presencia en redes sociales

\begin{tabular}{|c|c|c|c|c|c|c|c|c|c|c|c|c|}
\hline \multirow[b]{2}{*}{ Editorial } & \multicolumn{4}{|c|}{ Facebook } & \multicolumn{4}{|l|}{ Twitter } & \multicolumn{4}{|l|}{ Instagram } \\
\hline & Fans & Post & 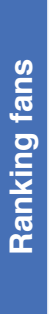 & 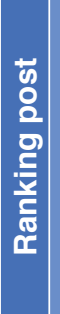 & Seguidores & Tuits & 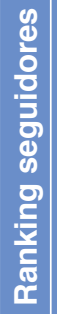 & 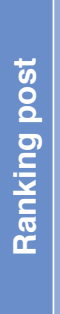 & Seguidores & Publicaciones & 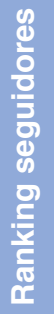 & 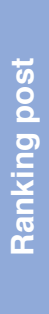 \\
\hline $\begin{array}{l}\text { Editorial } \\
\text { Planeta }\end{array}$ & 252.016 & 396 & 1 & 3 & 571.468 & 26.132 & 1 & 3 & 86.571 & 168 & 1 & 1 \\
\hline $\begin{array}{l}\text { Alianza } \\
\text { Editorial }\end{array}$ & 204.258 & 517 & 2 & 1 & 412.790 & 42.568 & 2 & 1 & 31.137 & 65 & 3 & 6 \\
\hline $\begin{array}{l}\text { Literatura } \\
\text { Random } \\
\text { House }\end{array}$ & 44.191 & 467 & 3 & 2 & 26.625 & 37.539 & 6 & 2 & 17.065 & 68 & 5 & 5 \\
\hline Siruela & 39.026 & 103 & 4 & 8 & 100.795 & 81 & 5 & 7 & 291 & 5 & 8 & 8 \\
\hline $\begin{array}{l}\text { Editorial } \\
\text { Seix Barral }\end{array}$ & 20.231 & 113 & 5 & 7 & 104.982 & 20.947 & 4 & 4 & 19.646 & 84 & 4 & 4 \\
\hline $\begin{array}{l}\text { Espasa } \\
\text { Libros }\end{array}$ & 17.322 & 173 & 6 & 5 & 122.081 & 9.630 & 3 & 6 & 43.771 & 93 & 2 & 3 \\
\hline $\begin{array}{l}\text { Harlequín } \\
\text { lbérica }\end{array}$ & 14.270 & 238 & 7 & 4 & 5.517 & 35 & 8 & 8 & 672 & 100 & 7 & 2 \\
\hline $\begin{array}{l}\text { Ediciones } \\
\text { Minotauro }\end{array}$ & 10.255 & 113 & 8 & 6 & 18.246 & 10.097 & 7 & 5 & 882 & 47 & 6 & 7 \\
\hline
\end{tabular}

Fuente: elaboración propia a partir de Fanpage Karma.

Dado que las editoriales en su estrategia de marketing digital para las distintas redes sociales consideradas tiene que hacer frente a la incertidumbre vinculada al adecuado impacto del contenido generado y a la ausencia de control sobre la reacción de los usuarios de la red, se hace preciso evaluar el nivel de engagement para determinar el compromiso adquirido por parte de sus fans y seguidores, ya que resulta ser más decisivo en el éxito de su política de marca online que un elevado número de fans y seguidores (Mutter, 2011).

\subsection{Análisis de la variable engagement}

Una vez vista la presencia en redes sociales de las editoriales estudiadas se procede a analizar su engagement (ver tabla 11).

De las tres redes sociales evaluadas, es Instagram la que ofrece un mayor nivel de engagement para todas y cada una de las editoriales estudiadas, sin excepción. Esto es especialmente significativo si se tiene en cuenta que dicha red es la que cuenta, para cada editorial, con un menor número de seguidores y publicaciones (ver tabla 11). 
Tabla 11. Ranking de editoriales en función del engagement

\begin{tabular}{|c|c|c|c|c|c|c|c|c|}
\hline \multirow{2}{*}{ 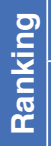 } & \multicolumn{2}{|c|}{ Facebook } & \multirow{2}{*}{ 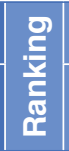 } & \multicolumn{2}{|c|}{ Twitter } & \multirow{2}{*}{ 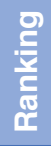 } & \multicolumn{2}{|c|}{ Instagram } \\
\hline & Editorial & Engagement & & Editorial & Engagement & & Editorial & Engagement \\
\hline 1 & Espasa Libros & $0,53 \%$ & 1 & $\begin{array}{l}\text { Ediciones } \\
\text { Minotauro }\end{array}$ & $0,47 \%$ & 1 & $\begin{array}{l}\text { Ediciones } \\
\text { Minotauro }\end{array}$ & $4,14 \%$ \\
\hline 2 & $\begin{array}{l}\text { Ediciones } \\
\text { Minotauro }\end{array}$ & $0,5 \%$ & 2 & Alianza Editorial & $0,39 \%$ & 2 & $\begin{array}{l}\text { Editorial } \\
\text { Planeta }\end{array}$ & $1,61 \%$ \\
\hline 3 & Editorial Planeta & $0,36 \%$ & 3 & $\begin{array}{l}\text { Literatura } \\
\text { Random House }\end{array}$ & $0,18 \%$ & 3 & Espasa Libros & $1,17 \%$ \\
\hline 4 & Alianza Editorial & $0,13 \%$ & 4 & $\begin{array}{l}\text { Editorial Seix } \\
\text { Barral }\end{array}$ & $0,15 \%$ & 4 & $\begin{array}{l}\text { Editorial Seix } \\
\text { Barral }\end{array}$ & $1,14 \%$ \\
\hline 5 & Editorial Seix Barral & $0,09 \%$ & 5 & Espasa Libros & $0,12 \%$ & 5 & Alianza Editorial & $0,92 \%$ \\
\hline 6 & Siruela & $0,06 \%$ & 6 & Editorial Planeta & $0,06 \%$ & 6 & $\begin{array}{l}\text { Literatura } \\
\text { Random House }\end{array}$ & $0,72 \%$ \\
\hline 7 & $\begin{array}{l}\text { Literatura Random } \\
\text { House }\end{array}$ & $0,04 \%$ & 7 & $\begin{array}{l}\text { Harlequín } \\
\text { lbérica }\end{array}$ & $0,01 \%$ & 7 & $\begin{array}{l}\text { Harlequín } \\
\text { Ibérica }\end{array}$ & $0,35 \%$ \\
\hline 8 & Harlequín Ibérica & $0,02 \%$ & 8 & Siruela & $0,0 \%$ & 8 & Siruela & $0,27 \%$ \\
\hline
\end{tabular}

Fuente: elaboración propia a partir de Fanpage Karma.

El hecho de que Instagram sea una red social donde lo que domina en el contenido, por encima de cualquier otra cosa, es la imagen, podría explicar los resultados generales de engagement tan elevados, confirmando así los resultados obtenidos en otras investigaciones (Hansson, Wrangmo y Søilen, 2013; Sabate et al., 2014; Kwok y Yu, 2013).

Otro aspecto reseñable es que, salvo algunas pocas excepciones, la posición en el ranking de engagement de una red social no tiene por qué verse equiparada en las demás redes sociales.

\section{Conclusiones}

Este estudio tenía como objeto analizar, por medio de la aplicación del modelo PRGS, el impacto de Facebook, Twitter e Instagram en la estrategia de marketing digital de las empresas editoriales españolas, considerando tres dimensiones: a) atracción de usuarios, b) generación de contenidos, y c) compromiso de los usuarios con la marca.

En cuanto a la atracción de usuarios, de los resultados obtenidos se desprende que la red social Facebook es la que más fans genera a las editoriales, frente a Twitter e Instagram, cuya capacidad para atraer usuarios es, de momento, sensiblemente menor. Sin embargo, la tendencia para atraer seguidores es claramente creciente en Instagram, mientras que en Facebook y Twitter parece producirse un cierto estancamiento, agotamiento o alcance de un techo en las editoriales monitorizadas.

En relación a la generación de contenidos por parte de las distintas marcas editoriales evaluadas, se concluye de los resultados que la red social Twitter es la más aprovechada por las marcas editoriales para generar contenidos, seguida de Facebook e Instagram. Puede que este resultado tenga que ver con el elevado volumen de tuits generados y la pérdida de visibilidad de los mensajes emitidos en un corto plazo de tiempo, lo que movería a las editoriales a intensificar la acción de comunicación en dicha red.

La tasa o ratio de actividad, como indicador que combina generación de contenidos y usuarios, subraya la intensidad de uso de Twitter por parte de las editoriales evaluadas, frente a las otras redes analizadas. 
En lo tocante al compromiso que las marcas editoriales logran alcanzar por parte de sus fans y seguidores en las diferentes redes sociales, los resultados apuntan a Instagram como la red donde se obtienen mejores resultados para todas ellas, sin excepción. Este potencial de Instagram para generar compromiso por parte de los usuarios podría estar relacionado con el dominio de la imagen en sus contenidos.

Finalmente, los datos ponen de manifiesto que liderar una red social no implica necesariamente liderar las demás, lo que conduce a una reflexión sobre la adaptación del contenido no solo a la red sino al tipo de usuarios que "habitan" en ella. Por eso, a pesar de los efectos ventajosos del marketing a través de las redes sociales, se necesita cierta precaución. Las redes sociales no se pueden gestionar como un medio de comunicación convencional y no se debe asumir que los resultados positivos están garantizados. En este contexto, para captar la atención e interés de los usuarios de las diferentes redes sociales y teniendo presente la vertiginosa evolución de las actualizaciones en el entorno digital, las editoriales deberían apostar por una estrategia diferenciada para cada una de las redes sociales en las que tengan presencia, ofreciendo información atractiva, dinámica y constante para los grupos de usuarios de cada una ellas. Esta necesidad de diferenciar la información que se comunica a los usuarios de las redes sociales es especialmente importante en el caso de Instagram, al ser la red social con el mayor crecimiento en popularidad durante los últimos años habiéndose situado en un porcentaje de uso en España del 9,28\% en el año 2015, el 30,89\% en el año 2016, el 42,67\% en el año 2017 y alcanzar el 45,58\% en el año 2018 (Herrera et al., 2019).

Como se puede derivar de este trabajo, cualquier acción promocional o campaña que una marca editorial pretenda desplegar en redes sociales debe mirar más allá de una cierta obsesión por generar contenidos indiscriminadamente, aumentar el número de seguidores o conseguir más "me gusta". Una estrategia optima pasa por profundizar en las acciones que promueven un mayor nivel de compromiso, convirtiéndolo en demanda para los productos editoriales. Todo ello implica que las editoriales deben: a) intensificar la ratio de actividad, concentrándose más en la calidad del numerador (generación de contenidos -posts, tuits y publicaciones-) que en el denominador (fans o seguidores), es decir, mantener una comunicación fluida, sugerente, proactiva y regular con los fans y seguidores, y b) profundizar en las estrategias STP (Segmentation, Targeting and Positioning) orientadas a los fans y seguidores dentro de cada red social. Lo primero se puede lograr a través de un análisis profundo de los elementos diferenciales en las formas de comunicar e interactuar dentro de cada red. Si en los mass media convencionales era evidente que el canal modulaba en forma y fondo el mensaje, en los nuevos canales de comunicación e interacción virtual no solo se mantienen, sino que se profundizan las diferencias, lo que conlleva evaluar estrategias de marketing adaptadas a cada red social, como ya se apuntó anteriormente. Lo segundo implica ver cada red social como un mercado que tendrá que ser segmentado partiendo de un perfil general de sus usuarios para identificar aquellos segmentos de la red que resulten potencialmente atractivos para la editorial de cara a situarlos como objetivos -sin dejar de cumplir con las exigencias de cualquier segmento comercialmente relevante, es decir, que sean identificables, accesibles, rentables, diferentes y posibles de servir- para posicionarse en él. Dado que el posicionamiento implica ocupar un espacio en la conciencia del usuario o consumidor potencial, es especialmente importante cuidar la adaptación del mensaje al canal: solo de ese modo se podrá consolidar un posicionamiento óptimo.

De lo anteriormente indicado, se concluye que una intervención activa y frecuente en Instagram, Facebook y Twitter es esencial para desarrollar una estrategia efectiva de marketing de contenidos, sin descuidar el hecho de que las diversas redes sociales generan diferentes niveles de interacción. Por ejemplo, Twitter puede servir como un canal de comunicación e información de los eventos de las editoriales más adecuado que los restantes, mientras que Instagram o Facebook pueden dar cobertura al desarrollo del evento editorial de modo más amplio y visual. 
Hay algunas limitaciones a considerar en este estudio que abrirían nuevas líneas de investigación: a) se han considerado solo las 25 primeras editoriales en publicación de literatura, por lo que para investigaciones futuras se podría analizar a las editoriales independientes que no formen parte de algún grupo editorial; b) sería útil estudiar a las editoriales especializadas en otras materias, como por ejemplo, en libro académico, y c) sería interesante llevar a cabo un análisis de contenido para examinar las publicaciones e interacciones que se realizan en las redes sociales del sector editorial a través de softwares de investigación cualitativa, como Atlas o Nvivo.

Dado el peso de la industria editorial española a nivel europeo y dada su proyección internacional (Magadán y Rivas, 2019) y su progresiva apuesta por los nuevos espacios de comunicación digital, se hace cada vez más necesaria la investigación sobre su peso en las estrategias de marketing editorial digital.

\section{Bibliografía}

Alalwan, A., Rana, N., Dwivedi, Y., y Algharabat, R. (2017). Social media in marketing: A review and analysis of the existing literature. Telematics and Informatics, 34 (7), 1177-1190. https://doi. org/10.1016/j.tele.2017.05.008

Algharabat, R., Alalwan, A., Rana, N., y Dwivedi, Y. (2017). Three dimensional product presentation quality antecedents and their consequences for online retailers: The moderating role of virtual product experience. Journal of Retailing and Consumer Services, 36, 203-217. https:// doi.org/10.1016/j.jretconser.2017.02.007

Berlo, D. (1960). The process of communication: An introduction to theory and practice. Holt Rinehart and Winston. New York.

Buhalis, D., y Mamalakis, E. (2015). "Social media return on investment and performance evaluation in the hotel industry context". En: IisTussyadiah y Alessandro Inversini (eds) Information and Communication Technologies in Tourism 2015. Springer, Cham. https://doi. org/10.1007/978-3-319-14343-9_18

Burton, S., y Soboleva, A. (2011). Interactive or reactive? Marketing with Twitter. Journal of Consumer Marketing, 28 (7), 491-499. https://doi.org/10.1108/07363761111181473

Carreiro, E. (2010). Electronic books: how digital devices and supplementary new technologies are changing the face of the publishing industry. Publishing Research Quarterly, 26 (4), 219-235. http://doi.org/10.1007/s12109-010-9178-z.

Castronovo, C., y Huang, L. (2012). Social media in an alternative marketing communication model. Journal of Marketing Development and Competitiveness, 6 (1), 117-134.

Chatterjee, P. (2011). Drivers of new product recommending and referral behavior on social network sites. International Journal of Advertising, 30 (1), 77-101. https://doi.org/10.2501/IJA30-1-077-101

Chu, S.-C. (2011). Viral Advertising in Social Media: Participation in Facebook Groups and responses among college-aged users. Journal of Interactive Advertising, 12 (1), 30-43. https://doi. org/10.1080/15252019.2011.10722189

Coulter, K., y Roggeveen, A. (2012). "Like it or not" Consumer responses to word-of-mouth communication in on-line social networks. Management Research Review, 35 (9), 878-899, https://doi.org/10.1108/01409171211256587 
Culnan, M., McHugh, P., y Zubillaga, J. (2010). How large U.S. companies can use twitter and other social media to gain business value. MIS Quarterly Executive, 9 (4), 243-259.

Cvijikj, I., Spiegler, E., yMichahelles, F. (2013). Evaluation framework for social media brand presence. Social Network Analysis and Mining, 3 (4), 1325-1349. https://doi.org/10.1007/s13278-013-0131-y

Cvijikj, I., y Michahelles, F. (2013). Online engagement factors on Facebook brand pages. Social Network Analysis and Mining, 3(4), 843-861. https://doi.org/10.1007/s13278-013-0098-8

Del Fresno, M. (2014). Haciendo visible lo invisible: visualización de la estructura de las relaciones en red en Twitter por medio del análisis de redes sociales. El profesional de la información, 23 (3), 246-252. http://dx.doi.org/10.3145/epi.2014.may.04

Di Gangi, P., Wasko, M., y Hooker, R. (2010). Getting customers' ideas to work for you: Learning from Dell how to succeed with online user innovation communities. MIS Quarterly Executive, 9(4), 163-178.

Duffett, R. (2015). Facebook advertising's influence on intention-to-purchase and purchase amongst Millennials. Internet Research, 25(4), 498-526, https://doi.org/10.1108/IntR-01-2014-0020

Dwivedi, Y., Kapoor, K., y Chen, H. (2015). Social media marketing and advertising. The Marketing Review, 15 (3), 289-309. https://doi.org/10.1362/146934715X14441363377999

Filo, K., Lock, D., y Karg, A. (2015). Sport and social media research: a review. Sport Manage. Rev. 18 (2), 166-181. Sport Management Review, 18 (2), 166-181. https://doi.org/10.1016/j.smr.2014.11.001

Gao, Q., y Feng, C. (2016). Branding with social media: user gratifications, usage patterns, and brand message content strategies. Computers in Human Behavior, 63, 868-890. https://doi. org/10.1016/j.chb.2016.06.022

García Medina, I., Miquel-Segarra, S., y Navarro-Beltrá, M. (2018). El uso de Twitter en las marcas de moda. Marcas de lujo frente a marcas low-cost. Cuadernos.Info, (42), 55-70. https:// doi.org/10.7764/cdi.42.1349

Geho, P. R., y Dangelo, J. (2012). The evolution of social media as a marketing tool for entrepreneurs. The Entrepreneurial Executive, 17, 61.

Giraldo, C., y Martínez, S. (2017). Análisis de la actividad y presencia en facebook y otras redes sociales de los portales turísticos de las Comunidades Autónomas españolas. Cuadernos de Turismo, 39, 239-264. https://doi.org/10.6018/turismo.39.290521

Hanna, R., Rohm, A., y Crittenden, V. (2011). We're all connected: The power of the social media ecosystem. Business Horizons, 54(3), 265-273. https://doi.org/10.1016/j.bushor.2011.01.007

Hansson, L., Wrangmo, A., y Søilen, K. (2013). Optimal ways for companies to use Facebook as a marketing channel. Journal of Information, Communication and Ethics in Society, 11(2), 112-126. https://doi.org/10.1108/JICES-12-2012-0024

Hawkins, K., y Vel, P. (2013). Attitudinal loyalty, behavioural loyalty and social media: An introspection. The Marketing Review, 13(2), 125-141. https://doi.org/10.1362/14693471 3X13699019904605

He, W., Zha, S., y Li, L. (2013). Social media competitive analysis and text mining: A case study in the pizza industry. International Journal of Information Management, 3(3), 464-472. https://doi. org/10.1016/j.ijinfomgt.2013.01.001 
Hennig-Thurau, T., Malthouse, E., Friege, C., Gensler, S., Lobschat, L., Rangaswamy, A., y Skiera, B. (2010). The impact of new media on customer relationships. Journal of Service Research, 13(3), 311-330. https://doi.org/10.1177/1094670510375460

Herrera, L., Pérez, F., Valcarce, M., y García, J. (2019). Análisis de las redes sociales en el sector del fitness español: un estudio longitudinal. Materiales para la Historia del Deporte, (18), 122128.

Hibbert, B. (1999). Publishing and the media industries in the digital age. Journal of Policy, Regulation and Strategy for Telecommunications, Information and Media, 1(5), 393-403. https:// doi.org/10.1108/14636699910801151

Hinz, O., Skiera, B., Barrot, C., y Becker, J. (2011). Seeding strategies for viral marketing: an empirical comparison. Journal of Marketing, 75(6), 55-71.

Hudson, S., Huang, L., Roth, M., y Madden, T. (2016). The influence of social media interactions on consumer-brand relationships: a three-country study of brand perceptions and marketing behaviors. International Journal of Research in Marketing, 33(1), 27-41. https://doi. org/10.1016/j.ijresmar.2015.06.004

Huertas, A. y Marine-Roig, E. (2016). User reactions to destination brand contents in social media. Information Technology and Tourism, 15(4), 291-315. https://doi.org/10.1007/s40558-0150045-9

Huertas, A., y Marine-Roig, E. (2016). User reactions to destination brand contents in social media. Information Technology and Tourism, 15(4), 291-315. https://doi.org/10.1007/s40558-0150045-9

Information Resources Management Association (2018). Social media marketing: Breakthroughs in research and practice. IGI Global, Hershey, Pensilvania.

Interactive Advertising Bureau Spain (2013). I Estudio Actividad de las marcas en medios sociales. Madrid: IAB Research Spain. https://iabspain.es/investigacion/actividad-de-las-marcasen-medios-sociales

Islas, O. (2010). El valor de las principales marcas en la economía del conocimiento. Cuadernos. Info, (27), 75-84. https://doi.org/10.7764/cdi.27.24

Jayasingh, S., y Venkatesh, R. (2015). Customer engagement factors in Facebook brand pages. Asian Social Science, 11(26), 19-29. http://dx.doi.org/10.5539/ass.v11n26p19

Kaplan, A., y Haenlein, M. (2010). Users of the world, unite! The challenges and opportunities of social media. Business Horizons, 53(1), 59-68. https://doi.org/10.1016/j.bushor.2009.09.003

Kietzmann, J., Hermkens, K., McCarthy, I., y Silvestre, B. (2011). Social media? Get serious! Understanding the functional building blocks of social media. Business Horizons, 54(3), 241-251. https://doi.org/10.1016/j.bushor.2011.01.005

Kohli, C, Suri, R., y Kapoor, A. (2015). Will social media kill branding? Bus Horizons. 58(1), 35-44. https://doi.org/10.1016/j.bushor.2014.08.004

Kwok, L., y Yu, B. (2013). Spreading Social Media Messages on Facebook An Analysis of Restaurant Business-to-Consumer Communications. Cornell Hospitality Quarterly, 54(1), 84-94. https://doi.org/10.1177/1938965512458360 
Leeflang, P., Verhoef, P., Dahlström, P., y Freundt, T. (2014). Challenges and solutions for marketing in a digital era. European Management Journal, 32(1), 1-12Eur. https://doi. org/10.1016/j.emj.2013.12.001

Lichtenberg, J. (2011). In from the edge: the progressive evolution of publishing in the age of digital abundance. Publishing Research Quarterly, 27(2), 101-112. http://doi.org/10.1007/s12109-011-9212-9.

Magadán, M. y Rivas, J. (2019). Adaptación de la industria del libro en España al cambio tecnológico: pasado, presente y futuro de la digitalización. Información, Cultura y Sociedad, (40), 31-52. https://doi.org/10.34096/ics.i40.4996

Magadán, M., y Rivas, J. (2018). Digitization and business models in the spanish publishing industry. Publishing Research Quarterly, 34(3), 333-346. http://doi.org/10.1007/s12109-018-9593-0.

Mandelli, A., y Cantoni, L. (2010). Impacto de los medios sociales en la reputación corporativa: propuesta de un nuevo acercamiento metodológico. Cuadernos.Info, (27), 61-74. https://doi. org/10.7764/cdi.27.23

Mangold, G., y Faulds, D. (2009). Social media: The new hybrid element of the promotion mix. Business Horizons, 52(4), 357-365. https://doi.org/10.1016/j.bushor.2009.03.002

Martin, B., y Tian, X. (2016). Books, bytes and business: the promise of digital publishing. New York: Routledge.

Mutter, A. (2011). "Engagement: The New Digital Metric". Editor \& Publisher, October 13, 2011, https://goo.gl/k9GGZG

Nguyen, B., Yu, X., Melewar, TC y Chen, J. (2015). Brand innovation and social media: Knowledge acquisition from social media, market orientation, and the moderating role of social media strategic capability. Industrial Marketing Management, 51, 11-25. https://doi.org/10.1016/j. indmarman.2015.04.017

Oviedo-García, M. Á., Muñoz-Expósito, M., Castellanos-Verdugo, M., y Sancho-Mejías, M. (2014). "Metric proposal for customer engagement in Facebook". Journal of Research in Interactive Marketing, 8(4), 327-344. https://doi.org/10.1108/JRIM-05-2014-0028

Pérez-García, A., y Torres-Valdés, R. (2019). Las agencias de empleo y desarrollo local, y el uso de las redes sociales en la promoción turística relacional. Innovar, 29(72), 77-88. http://dx.doi. org/10.15446/innovar.v29n72.77933

Popp, B., y Woratschek, H. (2016). Introducing branded communities in sport for building strong brand relations in social media. Sport Management Review, 19(2), 183-197. https://doi. org/10.1016/j.smr.2015.06.001

Qualman, E. (2009). Socialnomics how social media transforms the way we live and do business. Hoboken: Wiley John \& Sons, Inc.

Rathore, A., Ilavarasan, V., y Dwivedi, Y. (2016) "Social media content and product co-creation: an emerging paradigm". Journal of Enterprise Information Management, 29(1), 7-18, https://doi. org/10.1108/JEIM-06-2015-0047

Rodríguez-Fernández, M. M., Sánchez-Amboage, E., Rodríguez-Vázquez, C., y MahauadBurneo, M. D. (2017). "Galician Spas in Facebook". En F. Freire, X. Rúas-Araújo, V. MartínezFernández, X. García (eds.), Media and Metamedia Management, 329-334. Cham: Springer. https://doi:10.1007/978-3-319-46068-0_43 
Rothwell, D. (2010). In the company of others: An introduction to communication. Oxford University Press. USA.

Sabate, F., Berbegal-Mirabent, J., Cañabate, A., y Lebherz, P. (2014). Factors influencing popularity of branded content in Facebook fan pages. European Management Journal, 32(6), 1001-1011. https://doi.org/10.1016/j.emj.2014.05.001

Safko, L. (2010). The social media bible: Tactics, tools, and strategies for business success. Hoboken: Wiley John \& Sons, Inc

Sánchez, M. Á., de Matos, N., y Correia, M. B. (2019). Evolution of the Presence and Engagement of Official Social Networks in Promoting Tourism in Spain. Journal of Spatial and Organizational Dynamics, 7(3), 210-225.

Sánchez-Amboage, E., Rodriguez-Fernández, M. M., Juanatey-Boga, Ó., y Martínez-Fernández, V. (2019). La comunicación de los destinos turísticos en los medios sociales. El caso de la España Verde. Revista Espacios, 40(11), 1-11.

Saxena, A., y Khanna, U. (2013). Advertising on social network sites: a structural equation modelling approach. Vision, 17(1), 17-25. https://doi.org/10.1177/0972262912469560

Terzi, N. (2011). The impact of e-commerce on international trade and employment. ProcediaSocial and Behavioral Sciences, 24, 745-753. http://doi.org/10.1016/j.sbspro.2011.09.010.

Williams, J., y Chinn, S. (2010). Meeting relationship-marketing goals through social media: A conceptual model for sport marketers. International Journal of Sport Communication, 3(4), 422437. https://doi.org/10.1123/ijsc.3.4.422

Wozniak, T., Stangl, B., Schegg, R., y Liebrich, A. (2017). The return on tourism organizations' social media investments: Preliminary evidence from Belgium, France, and Switzerland. Information Technology and Tourism, 17(1), 75-100. https://doi.org/10.1007/s40558-017-0077-4

Yoshida, M., Gordon, B., Nakazawa, M., y Biscaia, R. (2014). Conceptualization and measurement of fan engagement: Empirical evidence from a professional sport context. Journal of Sport Management, 28(4), 399-417. https://doi.org/10.1123/jsm.2013-0199

Zaglia, M. (2013). Brand communities embedded in social networks. Journal of Business Research, 32(2), 225-280. https://doi.org/10.1016/j.jbusres.2012.07.015

Zhang, M., Jansen, B., y Chowdhury, A. (2011). Business engagement on Twitter: a path analysis. Electronic Markets, 21(3), 161-175. https://doi.org/10.1007/s12525-011-0065-z

Zhu, Y.-Q., y Chen, H.-G. (2015). Social media and human need satisfaction: Implications for social media marketing. Business Horizons, 58(3), 335-345. https://doi.org/10.1016/j. bushor.2015.01.006

Zorkociova, O., y Vancova, L. (2016). The Phenomenon of Social Networks and the Effectiveness of Facebook Page Measuring (the Case of Slovakia). Economic Annals XXI, 160 (7-8), 83-87. https://doi:10.21003/ea.V160-16 